\title{
Pengaruh Kolaborasi Gizi dan Farmasi terhadap Tingkat Pengetahuan
}

\section{Diabetes Mellitus Lansia}

\author{
Ratna Wijayatri ${ }^{{ }^{*}}$, Yulinda Kurniasari ${ }^{2}$, Lulu Fathnatul Ulya ${ }^{2}$, Emelda ${ }^{3}$ \\ ${ }^{1}$ Farmasi S1, Fakultas IImu Kesehatan, Universitas Muhammadiyah Magelang \\ ${ }^{2}$ Gizi S1, Fakultas IImu-IImu Kesehatan, Universitas Alma Ata Yogyakarta \\ ${ }^{3}$ Farmasi S1, Fakultas IImu-IImu Kesehatan, Universitas Alma Ata Yogyakarta \\ Email: ratna.wijayatri@ummgl.ac.id, kurniasari.yulinda@almaata.ac.id, lulufathnatul@gmail.com, \\ emelda@almaata.ac.id
}

Korespondensi:

Ratna Wijayatri

Farmasi S1, Fakultas IImu Kesehatan, Universitas Muhammadiyah Magelang

ratna.wijayatri@ummgl.ac.id

\begin{abstract}
Abstrak
Diabetes Melitus (DM) merupakan penyakit menahun dan kronis yang pengobatannya memerlukan waktu yang lama. Penyakit DM memberikan dampak yang buruk untuk kesehatan karena adanya komplikasi yang serius baik mikrovaskuler maupun makrovaskuler. Hampir 50\% kasus DM dialami oleh pasien dengan usia 65 tahun keatas. DM pada usia lanjut berbeda secara metabolik dengan DM pada usia lainnya sehingga dibutuhkan pendekatan terapi yang berbeda pada kelompok ini. Hal ini dikarenakan pada usia lanjut telah mengalami kemunduran fisik dan mental yang berakibat pada penurunan kualitas hidup dan penurunan pemahaman dalam memahami perintah menggunakan obat. Metode CBIA (Community Based Intensive Aproach) yang bersinergi antara Gizi dan Farmasi diterapkan dalam peningkatan pengetahuan terhadap kadar gula darah dan pengontrolannya pada pasien usia lanjut yang menderita DM. Penelitian ini merupakan penelitian kuantitatif pre post test design, dengan kontrol design. Responden diambil dari 2 puskesmas di Bantul dengan metode purposive sampling, dan diperoleh 60 responden lansia yang masuk ke dalam kriteria inklusi.Hasil pengukuran tingkat pengetahuan setelah dilakukan intervensi berupa asuhan farmasi dan gizi yang bersama-sama dengan metode CBIA mengalami peningkatan dibandingkan kelompok kontrol. Tingkat pengetahuan responden sebelum diberikan intervensi terdapat 4 responden dengan pengetahuan rendah, 26 responden dengan pengetahuan sedang, 30 responden dengan pengetahuan tinggi. Mengalami peningkatan pengetahuan menjadi terdapat 58 dengan pengetahuan tinggi, dan 2 rendah. Hal ini menunjukkan adanya pengaruh pemberian intervensi CBIA yang bersinergi antara gizi dan farmasi dalam meningkatkan pengetahuan pasien lansia terhadap DM.
\end{abstract}

Kata Kunci: CBIA; Diabetes Mellitus; lansia; tingkat pengetahuan

INPHARNMED Journal, Vol.5, No.2, Tahun 2021, 1-7

Available from: http://ejournal.almaata.ac.id/index.php/INPHARNMED 
Ratna Wijayatri, Yulinda Kurniasari, Lulu Fathnatul Ulya, Emelda

Pengaruh Kolaborasi Gizi dan Farmasi terhadap Tingkat Pengetahuan DM pada Lansia

\title{
THE EFFECT OF COLLABORATIVE NUTRITIONIST AND PHARMACIST ON KNOWLEDGE LEVEL OF ELDERLY DIABETES MELLITUS
}

\begin{abstract}
Diabetes Mellitus (DM) is a chronic disease whose treatment takes a long time. DM has a bad impact on health because of serious complications, both microvascular and macrovascular. Almost 50\% of patients with type 2 DM are patients aged 65 years and over. $D M$ in the elderly is metabolically different from DM in other ages, so a different therapeutic approach is needed in this group. This is because the elderly have experienced physical and mental decline which results in a decrease in quality of life and a decrease in understanding the command to use the medicine. The CBIA (Community Based Intensive Approach) method which synergizes between nutritionist and pharmacist is applied to increase knowledge of blood sugar levels and their control in elderly patients suffering from diabetes. This research is a quantitative pre-post-test design study, with a control design. Respondents were taken from 2 health centers in Bantul by purposive sampling method, and 60 elderly respondents were obtained who fit the inclusion criteria. The level of knowledge of elderly patients on blood sugar control is very important to support the achievement of a good quality of life for elderly DM patients. The results of measuring the level of knowledge after the intervention in the form of pharmaceutical and nutritional care together with the CBIA method experienced a significant increase compared to the control group. The level of knowledge of respondents before the intervention was given there were 4 respondents with low knowledge, 26 respondents with moderate knowledge, 30 respondents with high knowledge. It has increased to 58 with high knowledge, and 2 with low knowledge. This shows the effect of providing CBIA interventions that synergize between nutritionists and pharmacists in increasing elderly patients' knowledge of DM.
\end{abstract}

Keyword: Diabetes Mellitus; CBIA; Elderly; knowledge level

Received: 1 Oktober 2021

Accepted: 13 Desember 2021

\section{PENDAHULUAN}

Peningkatan taraf kesehatan masyarakat di Indonesia berakibat pada peningkatan usia harapan hidup yang diiringi oleh meningkatnya populasi lansia ${ }^{1,2}$. Menurut World Health Organization tahun 2012 disebutkan bahwa di kawasan Asia Tenggara populasi lansia sebesar 8\% atau sekitar 142 juta jiwa. Pada tahun 2050 terjadi peningkatan populasi lansia menjadi 3 kali lipat ${ }^{3}$. Pasien lansia menurut WHO tahun 2012 adalah pasien yang mempunyai umur $\geq 60$ tahun $^{4}$. Saat ini jumlah usia lanjut mencapai 450 juta orang (7\% dari seluruh penduduk dunia) dan nilai ini diperkirakan akan terus meningkat. Metabolisme pada pasien lansia mengalami penurunan, sehingga menyebabkan terjadinya berbagai 
masalah kesehatan diantaranya penyakit jantung, hipertensi, asam urat dan diabetes mellitus ${ }^{5,6}$. Sekitar 50\% lansia mengalami intoleransi glukosa dengan kadar gula darah puasa normal. Diabetes Mellitus merupakan salah satu penyakit yang sering dijumpai pada usia lanjut ${ }^{7}$. Hampir 50\% pasien DM tipe 2 berusia 65 tahun ke atas ${ }^{8,9}$.

Insidensi Penyakit Diabetas Mellitus (DM) mengalami peningkatan khususnya untuk Diabetes Mellitus tipe 2 di banyak negara. Life style yang buruk, obesitas dan meningkatnya umur seseorang menjadi faktor penyebab terjadinya $\mathrm{DM}^{10}$. Seiring pertambahan usia lansia mengalami kemunduran fisik dan mental yang menimbulkan banyak konsekuensi. Selain itu kaum lansia juga mengalami masalah khusus yang memerlukan perhatian antara lain lebih rentan terhadap terjadinya komplikasi mikrovaskular dan makrovaskular dari $\mathrm{DM}^{11,12}$. Komplikasi ini dapat ditanggulangi dengan adanya pengobatan yang intensif dan baik dari pasien serta perbaikan lifestyle dari pasien ${ }^{13,14}$.

Pada usia lanjut telah mengalami kemunduran fisik dan mental yang berakibat pada penurunan penurunan pemahaman dalam memahami perintah menggunakan obat. Hal ini mempengaruhi penanganan yang diberikan yang akan berpengaruh pula terhadap kualitas hidup pasien DM pada lansia. Faktor-faktor degenerasi pada pasien lansia perlu menjadi pertimbangan dalam memberikan pengobatan $\mathrm{DM}^{15}$. Untuk meningkatkan kualitas hidup pada pasien DM lansia, diperlukan pendekatan khusus yaitu menggunakan metode CBIA (Community Base Intensif Approach) dengan harapan tujuan terapi dapat tercapai ${ }^{16,17}$.

Penyakit DM merupakan penyakit yang memerlukan terapi berkesinambungan. Peningkata pengetahuan akan meningkatkan keberhasilan terapi, keberhasilan dari terapi akan memberikan dampak positif dalam meningkatkan kualitas hidup pasien dan akan menekan terjadinya komplikasi dari penyakit diabetes. Pengelolaan penyakit ini memerlukan peran serta dokter, perawat, ahli gizi, dan farmasi ${ }^{18}$. Pemahaman yang baik dari pasien terkait pengobatan dan pola makan dapat menurunkan terjadinya perburukan dari penyakit DM dan resiko terjadinya komplikasi ${ }^{19}$. Terapi Gizi dan farmasi merupakan pilar penatalaksanaan $\mathrm{DM}^{20,21}$. Terapi Nutrisi Medis (TNM) merupakan bagian dari penatalaksanaan DM secara total. Setiap penyandang DM membutuhkan TNM yang sesuai dengan kebutuhan sehingga sasaran terapi DM dapat tercapai hal ini membutuhkan peran dari ahli gizi dalam pemberian asuhan gizi pada pasien $\mathrm{DM}^{22}$. 
Telaah awal yang diperoleh dari wawancara beberapa pasien pada beberapa puskesmas di bantul terhadap pasien lansia yang mengalami DM, menyebutkan bahwa pasien tidak memahami tentang pola makan yang baik dalam menanggulangi DM dan kepatuhan yang kurang dalam mengkonsumsi obat. Pasien lebih cenderung mengurangi frekuensi dan jumlah makan dibandingkan mengatur pola makan dengan frekuensi makan yang teratur dengan pengurangan porsi makan yang sesuai. Tujuan penelitian ini adalah untuk memberikan pengetahuan yang menyeluruh terkait gizi yaitu pola makan dan pada bidang ilmu farmasi yaitu kepatuhan dalam meminum obat, sehingga diharapkan dapat meningkatkan pengetahuan pasien dari dua sisi yaitu gizi dan farmasi sehingga meminimalkan terjadinya kegagalan terapi dan timbulnya efek samping hipoglikemia yang merupakan faktor paling banyak dalam menurunkan kepatuhan.

\section{METODE PENELITIAN}

Jenis penelitian yang digunakan adalah penelitian Pre-Post Quasi design yaitu melakukan pengamatan ataupun pengukuran terhadap berbagai variabel penelitian sebelum dilakukan perlakukan dan sesudah intervensi untuk melihat adanya perbedaan sebelum diberikan perlakuan dengan sesudah diberikan perlakuan. Desain ini bertujuan untuk mengevaluasi intervensi dengan melihat sebab-akibat dari sebuah intervensi terhadap outcome penelitian

\section{Populasi dan Sampel Penelitian}

Populasi adalah keseluruhan obyek yang diteliti ${ }^{5}$. Populasi dalam penelitian ini adalah seluruh lansia yang terdiagnosis DM yang rutin berobat di puskesmas Sedayu 1 dan 2 Kabupaten Bantul. Penelitian ini menggunakan teknik pengambilan sampel, yaitu accidental sampling, responden yang sesuai dengan kriteria inklusi ayitu pasien lansia dengan umur diatas 65 tahun, terdiagnosa diabetes mellitus, berobat rutin dan bersedia menjadi responden dimasukkan sebagai sampel utama dalam penelitian.

\section{Instrumen penelitian}

Pengumpulan data dalam penelitian ini menggunakan alat pengumpul data berupa kuesioner dalam melihat pengetahuan responden terkait DM 
Ratna Wijayatri, Yulinda Kurniasari, Lulu Fathnatul Ulya, Emelda

Pengaruh Kolaborasi Gizi dan Farmasi terhadap Tingkat Pengetahuan DM pada Lansia

\section{HASIL DAN PEMBAHASAN}

Responden yang terlibat dalam penelitian ini berjumlah 60 orang pasien lansia yang melakukan pengobatan rutin di puskesmas Sedayu baik Sedayu 1 dan Sedayu 2. Umur menjadi salah satu factor resiko terjadinya Diabetes Mellitus. Teknik yang digunakan dalam penelitian ini menggunakan metode accidental sampling yaitu memilih responden yang dijumpai saat penelitian berlangsung. Dengan criteria pasien Diabetes Mellitus, tidak menunjukkan gangguan mental, dan bersedia menjadi responden. Penelitian dimulai dengan diberikan pretest terlebih dahulu, untuk mengetahui tingkat pengetahuan responden terkait pengobatan pada Diabetes Mellitus dan pola makan yang harus mereka taati dalam pengobatan. Setelah dilakukan pretest, kemudian diberikan penyuluhan dengan metode CBIA yang terintegrasi antara apoteker dan ahli gizi.

Metode CBIA ini dilakukan dengan dasar bahwa pasien usia lanjut telah mengalami kemunduran fisik dan mental yang berakibat dan penurunan pemahaman dalam memahami perintah menggunakan obat sehingga dibutuhkan teknik khusus yang dapat memaksimalkan interaksi tenaga medis dan pasien sehingga pesan yang disampaikan kepada pasien dapat tersampaikan dengan baik dan benar. Metode CBIA yang kami lakukan adalah dengan melakukan teknik konseling yang sinergis antara kedua profesi yaitu profesi apoteker dan gizi dengan menggunakan lembar balik dan contoh obat-obatan. Sinergisistas ini dilakukan berdasarkan permasalahan bahwa pada pasien lansia terjadi peningkatan intoleransi glukosa sehingga penggunaan obat obat antidiabetik yang sebelumnya efektif dapat menjadi tidak efektif. Hal ini mempengaruhi penanganan yang diberikan yang akan berpengaruh pula terhadap kualitas hidup dari pasien DM pada lansia. Faktor-faktor degenerasi pada pasien lansia perlu menjadi pertimbangan dalam memberikan pengobatan DM(15). Karakteristik responden yang kami libatkan dalam penelitian ini berdasarkan jenis kelamin dapat dilihat pada Tabel 1.

Tabel I. Distribusi Frekuensi Responden Berdasarkan Jenis Kelamin

\begin{tabular}{cc}
\hline Jenis Kelamin & Jumlah $(\mathrm{n})$ \\
\hline Laki-laki & $25(41,67 \%)$ \\
Perempuan & $35(58,33 \%)$ \\
\hline
\end{tabular}

Perbandingan jenis kelamin responden menunjukkan responden perempuan mempunyai persentase yang lebih besar dibandingkan laki-laki, hal ini dikarenakan 
perempuan mempunyai kegemaran makan cemilan yang manis-manis dan roti- rotian dan banyak makan-makanan yang mempunyai kadar karbohidrat tinggi. Seperti data yang diperoleh pada saat wawancara, kebanyakan responden perempuan menyampaikan bahwa mempunyai kebiasaan makan cemilan. Berdasarkan penelitian Kurniawan tahun 2010 bahwa faktor resiko obesitas, pola makan, kurang aktivitas atau latihan fisik menyebabkan semakin tingginya kejadian Diabetes Mellitus pada perempuan ${ }^{23}$.

Metode pengambilan sampel pada panelitian yang kami lakukan menggunakan accidental sampling teknis penelitian yang kami lakukan dengan cara menunggu pasien datang ke Puskesmas Sedayu 1 dan 2 dan melakukan wawancara dengan terlebih dahulu meminta informed consent dari pasien dilanjutkan dengan memberikan pretest terkait dengan tingkat pengetahuann dan kualitas hidup dilanjutkan dengan pemberian intervensi edukasi secara CBIA sinergis antara ilmu farmasi dan gizi, dan kemudian dilakukan postest untuk melihat terkait pengetahuan dari responden setelah dilakukan intervensi. Hasil pretest dan postest yang kami kumpulkan dikategorikan ke dalam tingkat pengetahuan rendah jika skor pretest/ posttest < 6; kategori tingkat pengetahuan sedang jika nilai skor tingkat pengetahuan $<11$; dan kategori tingkat pengetahuan tinggi dengan skor $>11$.

Hasil pretest tingkat pengetahuan, sebelum diberikan intervensi mempunyai tingkat pengetahuan yang bervariasi, terdapat 4 responden yang mendapatkan nilai rendah dan 26 Responden mendapatkan nilai sedang, serta 30 responden mempunyai nilai tinggi. Setelah diberikan edukasi diperoleh hasil yaitu terjadinya peningkatan tingkat pengetahuan responden yaitu terdapat 58 responden masuk ke dalam kategori pengetahuan tinggi dan hanya 2 responden yang masih mempunyai tingkat pengetahuan rendah. Dibandingkan pada kelompok yang mendapatkan intetervensi terjadi peningkaan jumlah responden yang mempunyai tingkat pengetahuan tinggi tentang pengobatan diabetes dan pola makan yang harus mereka taati saat terapi. Untuk lebih jelasnya dapat dilihat pada Tabel 2.

Tabel II. Hasil Pretest dan post test responden pada pemberian Edukasi Gizi dan Farmasi menggunakan metode CBIA di Puskesmas Sedayu

\begin{tabular}{cccccc}
\hline \multicolumn{4}{c}{ Persentase tingkat pengetahuan } \\
\hline \multicolumn{3}{c}{ Sebelum edukasi CBIA } & \multicolumn{3}{c}{ Sesudah edukasi CBIA } \\
\hline Rendah & Sedang & Tinggi & Rendah & Sedang & Tinggi \\
4 & 26 & 30 & 2 & 0 & 58 \\
$(6,67 \%)$ & $(43,33 \%)$ & $(50 \%)$ & $(3,33 \%)$ & $(0 \%)$ & $(96,67 \%)$ \\
\hline
\end{tabular}


Dari hasil intervensi dapat dilihat bahwa ada peningkatan tingkat pengetahuan pada responden sebelum diberikan intervensi berupa asuhan gizi dan farmasi secara sinergis dengan metode CBIA. Pemberian edukasi dengan metode CBIA terbukti dapat memberikan pemahaman bagi responden, hal ini sesuai dengan penelitian yang dilakukan Suryati tahun 2011 yang menyebutkan bahwa pemberianedukasi secara CBIA dapat memahamkan oleh karena diberikan secara langsung dan tervisualisasi serta dilakukan pendampingan yang baik dibandingkan dengan metode ceramah saja ${ }^{24}$. Dari penggalian pertanyaan pada pretest dan post test banyak responden yang masih belum paham tentang hipoglikemia dan pola makan yang baik. Terdapat 15 kasus pada responden yang mengalami hipoglikemia tetapi tidak memahami penyebab dan pola makan yang harus di patuhi. Dari segi pengobatan sendiri sebagian responden sudah patuh dan memahami cara pengobatan tetapi tidak diimbangi dengan pola makan yang teratur sehingga menyebabkan terjadinya hipoglikemia. Berdasarkan penggalian masalah, pasien yang mengalami hipoglikemia belum memahami bahwa pengobatan rutin harus diimbangi dengan pola makan yang baik. Ketidak pahaman dari pasien baik dari dalam individu maupun di luar individu. Konseling sangat dibutuhkan sebagai media perantara yang dapat mengatasi berbagai ketidaktahuan dan ketidak pahaman dari pasien baik yang timbul dari dalam dan luar individu. Konseling sangat dibutuhkan untuk mengatasi permasalahan secara menyeluruh karena konseling dapat menciptakan kolaborasi antara tenaga kesehatan dan pasien ${ }^{25}$.

\section{KESIMPULAN DAN SARAN}

Terdapat peningkatan pengetahuan pada pemberian intervensi pemberian edukasi secara CBIA kolaborasi Farmasi dan Gizi, menjadi 58 responden yang berpengetahuan tinggi.

Hasil penelitian ini dapat menjadi rujukan penelitian selanjutnya dalam penerapan kolaborasi tenaga kesehatan dalam meningkatkan kualitas hidup dan faktor determinan yang dapat mempengaruhi pengetahuan pasien Diabetes Melitus terkait pengobatan dan manajemen diri.

\section{KONFLIK KEPENTINGAN}

Seluruh penulis menyatakan tidak terdapat potensi konflik kepentingan dengan penelitian dan atau publikasi artikel ini. 


\section{DAFTAR PUSTAKA}

1. World Health Organization (WHO). World Population Ageing 2017. United Nations. United Nations New York: Department of Economic and Social Affairs; 2017. 46 p.

2. World Health Organization (WHO). World Population Ageing 2019 [Internet]. World Population Ageing 2019. United Nations New York; 2019. Available from: http://link.springer.com/chapter/10.1007/978-94-007-5204-7_6

3. World Health Organization (WHO). Ageing and health [Internet]. United Nations New York; 2021.

4. Singh S, Bajorek B. Defining 'Elderly' in Clinical Practice Guidelines for Pharmacotherapy. Pharm Pract (Granada). 2014;12(4):1-9.

5. McLachlan AJ, Pont LG. Drug metabolism in older people - A key consideration in achieving optimal outcomes with medicines. Journals Gerontol - Ser A Biol Sci Med Sci. 2012;67 A(2):175-80.

6. Ruscin JM, Linnebur SA. Pharmacokinetics in Older Adults. MSD Man Prof Ed [Internet]. 2021.

7. Chentli F, Azzoug S, Mahgoun S. Diabetes mellitus in elderly. Indian J Endocrinol Metab. 2015;19(6):744-52.

8. Toplak H, Hoppichler F, Wascher TC, Schindler K, Ludvik B. Obesity and type 2 diabetes. Wien Klin Wochenschr. 2016;128(2):196-200.

9. US Department of Health and Human Services. National Diabetes Statistics Report, 2020. Natl Diabetes Stat Rep. 2020;2.

10. Fan W. Epidemiology in diabetes mellitus and cardiovascular disease. Cardiovasc Endocrinol. 2017;6(1):8-16.

11. Chao JJ, Xue YZ. Effect of a new health education model on continuous nursing in elderly patients with diabetes mellitus. Front Nurs. 2018;5(1):69-74.

12. Saftarina F. Case Report: Type 2 Diabetes Mellitus for the Elderly with Less Family Support. Rev Prim Care Pract Educ. 2021;22-6.

13. Gillies CL, Abrams KR, Lambert PC, Cooper NJ, Sutton AJ, Hsu RT, et al. Pharmacological and lifestyle interventions to prevent or delay type 2 diabetes in people with impaired glucose tolerance: Systematic review and meta-analysis. Br Med J. 2007;334(7588):299302.

14. Luthfa I, Aspihan M, Lathif MR. The Relationship Between Family Support and Quality of Life Improvement of Patients with Diabetes Mellitus in Semarang. J Ners. 2020;14(3):327.

15. Milita F, Handayani S, Setiaji B. Kejadian Diabetes Mellitus Tipe II pada Lanjut Usia di Indonesia (Analisis Riskesdas 2018 ). J Kedokt dan Kesehat [Internet]. 2021;17(1):9-20.

16. Hartayu TS, Mohamed Izham MI, Suryawati S. Improving type 2 diabetes patients' quality of life by using a community based interactive approach - diabetes mellitus strategy in Yogyakarta, Indonesia. J Pharm Heal Serv Res. 2012;3(2):95-102.

17. Setiadi AAP, Wibowo YI, Brata C, Setiawan E, Edukasi Kesehatan Berbasis Masyarakat: Model Pengawalan GeMa CerMat oleh Apoteker [Internet]. 2019.

18. Abdulrhim S, Sankaralingam S, Ibrahim MIM, Diab MI, Hussain MAM, Al Raey H, et al. Collaborative care model for diabetes in primary care settings in Qatar: a qualitative exploration among healthcare professionals and patients who experienced the service. 
BMC Health Serv Res. 2021;21(1):1-12.

19. Shrivastava SRBL, Shrivastava PS, Ramasamy J. Role of self-care in management of diabetes mellitus. J Diabetes Metab Disord. 2013;12(1):1.

20. Srivastava R, Wal P. The role of Pharmaceutical Care in Diabetes Management Contents Editorial Broad Editorial Message Message from ACPI Articles Page 02. Int J Community Pharm. 2016;4(2).

21. R.D.S AL, Chaloob R, Qasim QA, Al-Salman HNK. Populations knowledge of diabetes and the role of nutritional therapy in controlling the disease in Basrah city: A cross-sectional study of assessment. Int J Green Pharm [Internet]. 2019;13(3):299-305.

22. PERKENI. Pedoman Pengelolaan dan Pencegahan Diabetes Melitus Tipe 2 Dewasa di Indonesia. Glob Initiat Asthma [Internet]. 2015;46.

23. Qin L, Knol MJ, Corpeleijn E, Stolk RP. Does physical activity modify the risk of obesity for type 2 diabetes: A review of epidemiological data. Eur J Epidemiol. 2010;25(1):5-12.

24. Sri S. Meningkatkan Keterampilan Memilih Obat Dengan Metode CBIA. Yogyakarta: UGM; 2012.

25. Lubis. Memahami Dasar-Dasar Konseling dalam Teori dan Praktek. Jakarta: Kencana Prenada Media Group; 2011. 